logical studies are at once shrewd and sound, and the same qualities of insight and judgment are combined with accuracy in his extensive contributions to the systematics of the Crustacea. His volume on this class in Lankester's "Treatise on Zoology" reveals the width of his erudition and is still indispensable to all students of the Crustacea. Dr. Calman's services to zoology have, of course, not been limited to the group in which he has specialized. His address to Section D revealed his interest in the contribution of taxonomy to the greatest zoological problems, and his work at the Museum has shown grasp of and sympathy with the study of all parts of the animal kingdom. In retiring, Dr. Calman takes with him the best wishes of all those to whom his friendly help has been extended, and their hope for much further contribution from him to his science. Mr. M. A. C. Hinton, assistant keeper of zoology in the Museum, will succeed Dr. Calman.

\section{Opening of B.B.C. Television Service}

ON Monday, November 2, the high definition television service of the British Broadcasting Corporation was officially inaugurated by Major the Right Hon. G. C. Tryon, H.M. Postmaster-General. This event marks the end of the first experimental period of the television service from the Alexandra Palace, which began during the radio exhibition at Olympia last August. During this experimental period considerable progress was made in the technique of transmitting both direct scenes and cinematograph films, using alternately the Baird and the Marconi-E.M.I. systems of transmission. During the opening ceremony, the Postmaster-General and others had to address themselves not only to listeners but also to viewers within a radius of some 25 miles. As reported in The Times, Mr. R. C. Norman, chair. man of the B.B.C., was the first to use the word 'viewers' in its new meaning on this occasion. $\mathrm{He}$ recalled the fact that almost exactly fourteen years ago, the British Broadcasting Company, as it was then called, transmitted its first broadcasting programme from Marconi House. Following the formal speeches, Monday's programme included a variety item and an excerpt from British Movietone news. As Mr. Norman pointed out, this simple ceremony and programme may possibly seem rather primitive a few years hence to those who are able to recall it; at the present time, however, there is cause for satisfaction on the part of those responsible for the development of this new technique in radio broadcasting.

\section{The Steam Locomotive}

Aт a meeting of the Institution of Mechanical Engineers on October 23, Sir H. Nigel Gresley was installed as president and delivered an address in which he took, as his main theme, the recent developments in steam locomotives. Forty years ago, the late Mr. Samuel Johnson, in the same position, gave a comprehensive address on the mechanical equipment of British railways, and Sir Nigel pointed out that at that time there were no British locomotives weighing, with tender, 100 tons, no engine with a higher steam pressure than $175 \mathrm{lb}$. per sq. in., none with a grate area exceeding $27 \mathrm{sq}$. ft. and no express engine with a higher tractive effort than 19,400 lb. To-day, weights of 165 tons, steam pressures of $250 \mathrm{lb}$. per sq. in., grate areas of $50 \mathrm{sq}$. ft. and tractive efforts of more than $40,000 \mathrm{lb}$. have been attained in Great Britain. In these forty years, the power of British locomotives has increased by a hundred per cent, and the remarkable fact is that these increases have been effected within the limits of the standard track and the even more restrictive limits of the British loading gauge. On American and Continental railways having the same $4 \mathrm{ft} .8 \frac{1}{2} \mathrm{in}$. track, locomotives can be built so much higher and wider that engines of double the weight and power of the most modern English engines are quite common. To show the present relative position of steam, Diesel and electric methods of propulsion, numerous figures were given of locomotives and their performances in service, in particular those relating to the Flying Hamburger. After prolonged trials, this train was put into operation between Hamburg and Berlin in May 1933. It consists of two articulated coaches on three bogies, is driven by two Maybach 410 h.p. Diesel engines directly coupled to electric generators, and does the journey at an average speed of 77.4 m.p.h. Its smooth running over long distances at a speed of 100 m.p.h. suggested an inquiry as to the possibility of experimenting with extra high speed travel on the London and North Eastern Railway in Great Britain.

The curves, gradients and speed restrictions on the 268-mile line from King's Cross to Newcastle constitute a more difficult problem than that of the Berlin-Hamburg route, and the makers of the Dieselelectric train estimated that the time required would be 4 hours $15 \frac{1}{2} \mathrm{~min}$. on the down journey and 4 hours $17 \mathrm{~min}$. up. On the other hand, it was ascertained that a steam locomotive of the "Pacific" type could accomplish it in four hours, and so it was that The Silver Jubilee train came to be designed. The engine was made sufficiently powerful to maintain a good speed on the up gradients, for the saving of time in increasing speed from 60 to 90 m.p.h. on a downhill run of 15 miles is only 5 minutes, whereas by maintaining 60 m.p.h. instead of dropping to 30 on the uphill run, 15 minutes are gained. This locomotive exerts a total of 1,750 h.p. when taking a rising gradient of 1 in 200 at 80 m.p.h. It was also mentioned that scale models of the stream-lined engine of The Silver Jubilee and of the ordinary "Pacific" type have been under test at the National Physical Laboratory to determine the head-on wind resistances in each case. The horse-power required to overcome these wind resistances has been found to vary from $56 \cdot 39$ and $97 \cdot 21$ respectively at 60 m.p.h. to $881 \cdot 48$ and $1,520.8$ at 120 m.p.h., and a remarkable result indicated by the table of figures given is that, within these limits of speed, the saving of power effected by stream-lining is a practically constant proportion, namely $42 \cdot 1$ per cent. 